\title{
The effect of patient care education on burden of care and the quality of life of caregivers of stroke patients
}

This article was published in the following Dove Medical Press journal: Journal of Multidisciplinary Healthcare

\section{Hekmatpou' \\ E Mohammad Baghban' \\ L Mardanian Dehkordi²}

'Nursing Department, Arak University of Medical Sciences, Arak, Iran; ${ }^{2}$ Nursing Department, Isfahan University of Medical Sciences, Arak, Iran
Correspondence: D Hekmatpou Nursing department. Arak University of Medical Sciences. Sardasht Sq. Arak, Iran Tel +989l8 I6I 6539

Emaildr_hekmat@arakmu.ac.ir
Background: Care for stroke patients at home is a very complicated and tough activity. Objective: The study was conducted to examine the effect of patient care education on burden of care and quality of life of caregivers of stroke patients.

Materials and methods: The study was an educational trial conducted on 100 caregivers of the stroke patients in Al-Zahra educational hospital, Isfahan, Iran. The intervention group received some training to empower caregivers in family-oriented care in form of an educational counseling program. Data were collected and analyzed using the questionnaires, including demographic, quality of life Short Form-36, and Zarit burden of care questionnaires.

Results: The mean ages of caregivers were 48.52 years in the intervention and 45.14 years in the control groups. The results indicated significant differences in mean of quality of life and burden of care in the caregivers of the intervention group after intervention $(P<0.01)$, which was insignificant in the control group. The average burden on the caregivers of both groups was significantly associated with health status, economic status, marital status, the number of children, care hours, care days, and familial relationship of the caregivers with the patients $(P<0.01)$ before intervention. In addition, quality of life of both groups was significantly related to their health status $(P<0.01)$ before intervention.

Conclusion: Patient care education reduced the burden of care and improved quality of life of the caregivers of stroke patients. Thus, to reduce the complications of caring for stroke patients, family education should be the priority of nursing and discharging procedures.

Keywords: burden of care, family, stroke, quality of life

\section{Introduction}

Stroke is the commonest vascular disorder and the third leading cause of adult mortality in the world..$^{1-4}$ This is significantly higher in Iran compared with the Western countries and occurs at an earlier age. ${ }^{5}$ Its prevalence in Iran is reported to be 139 per 100,000 people. ${ }^{6}$ Stroke is one of the most important causes of chronic and severe disabilities, ${ }^{7}$ and most of the patients with it suffer from a range of debilitating neurological disorders like cognitive, mental, emotional, communicative or physical, functional, and social disabilities causing many problems for their families. ${ }^{8}$ Thus, these patients will be dependent on their families for their physical and emotional needs after discharge from the hospital. ${ }^{9}$

Managing this chronic disorder at home is a very complex activity in need of special care and services. ${ }^{10}$ Caring for such patients causes psychological and emotional distresses for caregivers. ${ }^{11}$ In addition, the risk of chronic diseases in these people is twice that of the people of their same age and gender, which can change their quality 
of life. ${ }^{12}$ Issues, such as mental, psychological, physical, and socioeconomic disorders, threaten the health of the family and cause a feeling of lack of control over life affairs. The aftermath of problems are defined as "care burden". ${ }^{13}$ In other words, burden of care involves physical, emotional, and psychological hardship that caregivers of family members may experience when caring for their patients. ${ }^{14}$ The burden of care may impose serious harm to the mental and physical health of family members, of which hypertension, cardiovascular disorders, and immune deficiency are some. ${ }^{15}$ The main caregivers are exposed to more stress as the patient's biological, social, and psychological needs is prioritized in comparison to their own; therefore, the caregivers are in the group of people who are exhausted due to excessive pressures and demands with their quality of life decreasing. ${ }^{16}$

According to various studies, the highest burden of care for family members (father, mother, sister, ...) is imposed on the spouse and children of stroke patients. This may result in a reduction in their physical and mental function, with no desirable services provided to the patients. ${ }^{15}$ It is estimated that the burden of care for the family of people with stroke is increasing in the world due to the lack of support from the organizations and associations. ${ }^{17}$ Regarding this, the present study was conducted to evaluate the effect of patient care education on burden of care and quality of life of caregivers of stroke patients.

\section{Methods}

\section{The study}

This was an educational trial study conducted to determine the effect of patient care education on the burden of care and quality of life in the family of stroke patients in Alzahra Hospital, Isfahan, Iran, in 2017. After the approval by the ethics committee of the Arak Medical University's Ethics Council (with the ethics code IR.ARAKMU.REC.1395.272), the informed consent was received from all the participants showing their willingness to participate in the study. The sampling was done using random block allocation and participants were divided into two groups of intervention and control (each group included 50 patients).

The inclusion criteria were, the desire of the caregiver to participate in the research, caregiver being a family member (father, mother, sister, ...), caregiver providing care for a stroke patient for at least 6 hours a day for at least 1 month, age of the caregiver being $>18$ years, and the presence of all or some of the stroke complications which the caregiver has faced in previous month. These complications were like sensory impairment, movement, swallowing, speech impairment, vision, and urinary and feces discharge problems in the patient. The exclusion criteria were the unwillingness to continue and the death of the patient or the caregiver.

\section{Sampling}

The sample size was determined according to a similar study, and based on the following formula:

$$
n=\frac{\left(t_{n-1, a / 2}+t_{n-1, \beta}\right)^{2}}{d^{2}}
$$

It included 100 patients assigned to two groups of control and intervention with 50 participants in each $(\alpha=0.05, \beta=0.2$, $\mathrm{d}=0.4937, \mathrm{~m} 1=21.26, \mathrm{~m} 2=24.23, \mathrm{sd} 1=4.29, \mathrm{sd} 2=4.26$ ).

The subjects were first selected using purposive sampling (after first month of the event), and after obtaining written informed consent (the consent forms were taken from family members of the patients; it was supposed to be filled by one of the parents or big brother or protector) and being included in the sampling, they were randomly assigned to two groups of intervention (A) and control (B) using randomized blocking method. First, the blocks with four parts (AABB, ABAB, ABBA, BBAA, BABA, BAAB, and so on) were designed. Then these blocks were randomly sorted and the individuals were assigned to two groups according to $\mathrm{A}$ and $\mathrm{B}$. This continued until the sample size was completed.

\section{Data collection tools}

A. The demographic questionnaire of the caregiver included age, sex, history of illness, marital status, educational level, economic status, number of children, time of care, number of days of care, and relation to the patient.

B. Zarit burden of care questionnaire.

This questionnaire examines the burden of care associated with the physical, psychological, economic, and social life status. The questionnaire consists of 22 questions, which includes a minimum score of 0 and a maximum of 88 . Classification of scores is as follows: no to low maintenance (0-20 points), low to moderate $(21-40)$, moderate to severe (41-60), and very high load (61-88).

C. The quality of life Short Form-36 (SF-36) quality of life questionnaire

This questionnaire has 36 questions and consists of eight scales, with each scale consisting of 2-10 items. The subscales of this questionnaire are as follows: physical functioning, physical health, emotional health, tiresome, emotional well-being, social functioning, pain, and general health. 


\section{Implementation}

After completing the demographic characteristics questionnaires, SF-36 quality of life, and Zarit burden of care, the intervention group received face-to-face training besides the routine training during two sessions of 1.5 hours in the hospital and a training booklet was provided to the caregiver. The booklet consists of 30 pages of nursing interventions for stroke patients written in an easy and practical language. The booklet was illustrated. Two telephone consultations were conducted with the intervention group at intervals of 3 days with two sessions of visits and practical training at home 1 week after the second telephone counseling. During each home visit, the researcher (student of Master of Science in Nursing) was the trainer of the caregivers and the patient was around during the training. The trainer responded to all related nursing intervention questions and caregiver did some practice on the patient under the supervision of the trainer. Then after 1 month, SF-36 quality of life, and Zarit burden of care questionnaires were again completed by the caregivers in the intervention group.

The control group completed demographic characteristics questionnaires, SF-36 quality of life, and Zarit burden of care questionnaires and received the routine training, which means the training of patients by the department staff in the center. After the study and data collection, all caregivers in control group were trained and the booklet also was given to them.

\section{Results}

As Table 1 shows, most caregivers of the stroke patients participating in this study were women ( $72 \%$ in the intervention group and $54 \%$ in the control group, $P=0.41$ ), and their mean age was 48.52 years in the intervention group and 45.14 years in the control group. Most of the participants were married (78\% in the intervention group and $70 \%$ in the control group, $P=0.83$ ). Moreover, $44 \%$ of both groups had an average economic status $(P=0.19$; Table 1$)$.

Table 2 shows the changes in burden of care in caregivers of stroke patients at the time before and after intervention (1 month). The table shows that the educational intervention of the present study could reduce the caring time of the caregiver in the intervention group from $67.84 \pm 4.23$ to $41.50 \pm 10.79$, which was significant $(P<0.01$; Table 2$)$.

Table 3 is the comparison of the mean of burden of care (personal, social, emotional, and economic) in caregivers of stroke patients before and after intervention, and Table 4 shows the factors affecting the level of burden of care in caregivers. According to these results, burden of care of stroke patients was significantly related to economic health, marital status, number of children, hours of care, care days, and the relationship of the caregivers with patients (Tables 3 and 4).

As a matter of fact, all the problems of the caregivers like: bad health status of the caregivers, marital status of

Table 2 Changes in burden of care in caregivers of stroke patients before and after intervention

\begin{tabular}{|l|l|l|l|}
\hline \multirow{2}{*}{ Group } & \multicolumn{2}{|l|}{ Burden of care } & \multirow{2}{*}{ Significance } \\
\cline { 2 - 3 } & $\begin{array}{l}\text { Before } \\
\text { intervention }\end{array}$ & $\begin{array}{l}\text { After } \\
\text { intervention }\end{array}$ & \\
\hline Intervention & $67.84 \pm 4.23$ & $41.50 \pm 10.79$ & $<0.01$ \\
Control & $61.60 \pm 11.30$ & $61.23 \pm 6.40$ & $<0.05$ \\
\hline
\end{tabular}

Table I Demographic information of the caregivers of stroke patients

\begin{tabular}{|c|c|c|c|c|}
\hline \multicolumn{2}{|l|}{ Variables } & \multicolumn{2}{|l|}{ Group } & \multirow[t]{2}{*}{ Significance } \\
\hline & & Intervention (\%) & Control (\%) & \\
\hline Age (years) & $\begin{array}{l}18-29 \\
30-39 \\
40-49 \\
50-59 \\
>60\end{array}$ & $\begin{array}{l}8(16) \\
14(28) \\
10(20) \\
13(26) \\
5(10)\end{array}$ & $\begin{array}{l}13(26) \\
8(16) \\
9(18) \\
13(26) \\
7(14)\end{array}$ & 0.79 \\
\hline Gender & $\begin{array}{l}\text { Male } \\
\text { Female }\end{array}$ & $\begin{array}{l}14(28) \\
36(72)\end{array}$ & $\begin{array}{l}23(46) \\
27(54)\end{array}$ & 0.13 \\
\hline Marital status & $\begin{array}{l}\text { Single } \\
\text { Married }\end{array}$ & $\begin{array}{l}\text { II (22) } \\
22(44)\end{array}$ & $\begin{array}{l}15(30) \\
16(32)\end{array}$ & 0.20 \\
\hline Educational level & $\begin{array}{l}\text { Sub-diploma } \\
\text { Diploma and associate's degree } \\
\text { Bachelor's and higher }\end{array}$ & $\begin{array}{l}13(26) \\
15(30) \\
22(44)\end{array}$ & $\begin{array}{l}18(36) \\
16(32) \\
16(32)\end{array}$ & 0.06 \\
\hline Economic status & $\begin{array}{l}\text { Poor } \\
\text { Average } \\
\text { Good }\end{array}$ & $\begin{array}{l}18(36) \\
22(44) \\
10(20)\end{array}$ & $\begin{array}{l}21(42) \\
22(44) \\
6(12)\end{array}$ & 0.19 \\
\hline
\end{tabular}


Table 3 Comparison of the mean of burden of care (individual, social, emotional, and economic) among caregivers of stroke patients before and after intervention

\begin{tabular}{|l|l|l|l|l|l|l|}
\hline Group & Variables & \multicolumn{2}{l|}{ Before } & \multicolumn{2}{l|}{ After } & Paired t-test \\
\hline Intervention & & SD & Mean & SD & Mean & P-value \\
\cline { 2 - 7 } & Individual & 12.32 & 66.20 & 8.44 & 47.00 & $<0.05$ \\
\cline { 2 - 7 } & Social & 11.17 & 64.60 & 9.09 & 46.86 & $<0.05$ \\
\cline { 2 - 7 } & Emotional & 12.55 & 69.93 & 3.92 & 38.53 & $<0.05$ \\
\cline { 2 - 7 } & Economic & 9.14 & 68.60 & 3.47 & 49.86 & $<0.05$ \\
\hline \multirow{5}{*}{ Control } & Individual & 12.51 & 68.93 & 10.12 & 67.53 & $>0.05$ \\
\cline { 2 - 7 } & Social & 11.91 & 67.60 & 12.69 & 67.86 & $>0.05$ \\
\cline { 2 - 6 } & Emotional & 12.42 & 67.93 & 9.90 & 66.53 & $>0.05$ \\
\cline { 2 - 6 } & Economic & 12.34 & 67.93 & 9.84 & 68.41 & $>0.05$ \\
\hline
\end{tabular}

Table 4 Correlation of not suitable demographic characteristics of caregivers in both groups with their burden of care before intervention

\begin{tabular}{|l|l|l|}
\hline Variables & $\begin{array}{l}\text { The correlation } \\
\text { coefficient }\end{array}$ & Sig. \\
\hline Health status of the caregivers (bad) & 0.45 & $<0.0 \mathrm{I}$ \\
Marital status of the caregivers (alone) & 0.28 & 0.03 \\
Economic status of the caregivers (bad) & 0.58 & $<0.0 \mathrm{I}$ \\
$\begin{array}{l}\text { Number of the children of the caregivers } \\
\text { (more than one) }\end{array}$ & 0.25 & $0.0 \mathrm{I}$ \\
$\begin{array}{l}\text { The relationship of the caregivers (father, } \\
\text { mother, sister, ...) }\end{array}$ & 0.23 & $0.0 \mathrm{I}$ \\
$\begin{array}{l}\text { Care hours of the caregivers } \\
\text { (many) }\end{array}$ & 0.31 & $<0.0 \mathrm{I}$ \\
$\begin{array}{l}\text { Care days of the caregivers } \\
\text { (many) }\end{array}$ & 0.55 & $<0.0 \mathrm{I}$ \\
\hline
\end{tabular}

the caregivers (to be alone), bad economic status of the caregivers, having two or more children, the relationship of the caregivers with the patients (father, mother, sister, ...), providing many hours of care, increasing the number of care days of the patient had a negative effect on their burden of care.

Table 5 shows changes in quality of life of caregivers of stroke patients before and after intervention. The intervention of the present study could increase quality of life of the caregiver in the intervention group from $50.64 \pm 5.23$ to 59.54 \pm 16.29 , which was significant $(P<0.01)$ (Table 5).

The results showed that the mean scores of quality of life and its sub-scales increased in the intervention group compared with the control group, except for physical function and pain that did not differ significantly (Tables 6).

\section{Discussion}

In line with the present study, in the study by Tabrizi et al, most of the caregivers were married. ${ }^{18}$ In the study by Gholizade et al, most of the caregivers were married too. ${ }^{19}$
Table 5 quality of life changes in caregivers of stroke patients before and after intervention

\begin{tabular}{|l|l|l|l|}
\hline \multirow{2}{*}{ Group } & \multicolumn{2}{|l|}{ Quality of life } & \multirow{2}{*}{ Significance } \\
\cline { 2 - 4 } & $\begin{array}{l}\text { Before } \\
\text { intervention }\end{array}$ & $\begin{array}{l}\text { After } \\
\text { intervention }\end{array}$ & \\
\hline Intervention & $50.64 \pm 5.23$ & $59.54 \pm 16.29$ & $<0.01$ \\
Control & $54.54 \pm 12.45$ & $57.13 \pm 17.99$ & $<0.05$ \\
\hline
\end{tabular}

The results of the two recent studies, in line with the results of the present study, show that, in relation to family members, married people have a more active role in caring for their patients, such as higher accountability compared with single people.

According to the results of the present study, patient care education has improved the burden of care in the caregivers of the patients. In a study, Gutiérrez-Maldonado et al examined the burden of care and general health in the families of schizophrenic patients with the results showing that the level of education has a significant relationship with the burden of care in the caregiver of these patients, meaning that the higher the level of caregivers' education, the lower the burden of care in them. ${ }^{20}$ Although education in this study meant general education (educational literacy), it shows that general education, as well as specialized care of the patient, is effective in enhancing the care burden. Thus, the results of the study by Maldonado et al can be consistent with the results of the present study. It should be noted that Tabrizi et al also conducted a study whose results confirmed the effectiveness of cognitive behavioral interventions in reducing the burden of care in Alzheimer patients' caregiver, ${ }^{21}$ confirming the result of this study.

Narimani ${ }^{22}$ examined the effect of teaching coping strategies on quality of life and burden of care of family caregivers in a stroke patient. Training coping strategies, like patient care education, is an educational program for reducing or 
Table 6 Mean quality of life and its dimensions in the intervention and control group before and after intervention

\begin{tabular}{|c|c|c|c|c|}
\hline \multirow[t]{2}{*}{ Group } & \multirow[t]{2}{*}{ Variables } & Before & After & Paired $t$-test \\
\hline & & SD \pm mean & SD \pm mean & $P$-value \\
\hline \multirow[t]{9}{*}{ Intervention group } & Quality of life & $50.64 \pm 5.23$ & $59.54 \pm 16.29$ & $<0.05$ \\
\hline & Physical functioning & $51.93 \pm 7.12$ & $52.24 \pm I I .45$ & $>0.05$ \\
\hline & Physical health & $53.14 \pm 9.7 \mid$ & $59.72 \pm 9.24$ & $<0.05$ \\
\hline & Emotional health & $50.11 \pm 6.45$ & $61.13 \pm 9.26$ & $<0.05$ \\
\hline & Tiresome & $50.39 \pm 7.24$ & $58.38 \pm 6.82$ & $<0.05$ \\
\hline & Emotional well-being & $47.49 \pm 8.71$ & $56.66 \pm I 1.24$ & $<0.05$ \\
\hline & Social functioning & $5 \mathrm{I} .80 \pm 4.6 \mathrm{I}$ & $57.83 \pm 11.24$ & $<0.05$ \\
\hline & Pain & $56.31 \pm 10.27$ & $55.64 \pm 9.36$ & $>0.05$ \\
\hline & General health & $49.19 \pm 7.51$ & $56.18 \pm 8.45$ & $<0.05$ \\
\hline \multirow[t]{8}{*}{ Control group } & Quality of life & $50.54 \pm 12.45$ & $49.13 \pm 17.19$ & $>0.05$ \\
\hline & Physical functioning & $54.83 \pm 7.45$ & $52.32 \pm 7.81$ & $>0.05$ \\
\hline & Physical health & $57.13 \pm 9.14$ & $58.32 \pm 4.81$ & $>0.05$ \\
\hline & Emotional health & $49.93 \pm 4.52$ & $51.14 \pm 4.73$ & $>0.05$ \\
\hline & Tiresome & $53.69 \pm 8.14$ & $52.37 \pm 9.53$ & $>0.05$ \\
\hline & Emotional well-being & $50.51 \pm 7.35$ & $52.20 \pm 7.41$ & $>0.05$ \\
\hline & Social functioning & $5 I .11 \pm 4.51$ & $49.37 \pm 7.78$ & $>0.05$ \\
\hline & Pain & $43.85 \pm 7.39$ & $48.61 \pm 7.55$ & $<0.05$ \\
\hline
\end{tabular}

improving the care burden. The average burden of care of the caregivers in post-test was significantly less than the pretest, showing the effectiveness of coping strategies training in reducing the burden of care. ${ }^{22}$ As stated previously, since coping strategies, such as patient care is an educational program, it is in line with the results of the present study in being effective in reducing the care burden. Arshi et $\mathrm{al}^{23}$ examined the relationship between the burden of care and family functioning in children with cancer. One of the subresults of this study was that the majority of caring parents with a cancerous child had non-academic studies, so Arshi et al stated that parental education was one of the factors affecting the burden of care. ${ }^{23}$ These results could confirm the result of the present study regarding the effectiveness of patient care education in improving the care burden.

According to previous studies, several factors are related to the care burden, of which the quality of interpersonal and patient relationships, cognitive ability of the patient, signs and symptoms of the patient's psychological and behavioral patterns, caring gender, and increasing adverse life events can be cited. ${ }^{24}$ The degree of burden of care experienced by caregivers depends on several factors, including physical and mental health, physical and mental illness, social life, ethics, and the income of the caregiver. Indeed, burden of care is one of the important concepts with many studies devoted to the family domain. ${ }^{25}$ All scholars believe that caregivers' burden of care is not confined to a unique concept, but as a multidimensional concept, it takes care of personal differences and adaptive trends. Some writers have defined the burden of care as an effect that providing care can have on mental health, physical, work or even economic caregivers or other family members. Increased burden of care is significantly connected to decreasing the health and quality of life of caregivers of stroke patients, especially in mental health and social functioning. ${ }^{26}$ The greatest burden of care is imposed upon family members who are spouses and children, and of course, this burden of care is much higher for women. ${ }^{15}$

In a study, Gholizade et al examine the effectiveness of patient care education on quality of life of caregivers of stroke patients in form of a randomized field trial. The results showed that the dimensions of quality of life of caregivers were significantly higher in the intervention group 1 month after the training compared with the control group. ${ }^{19}$ which was completely consistent with the results of our study. In addition, the results of this study showed that patient care education improves the dimensions of general, physical, and mental health in caregivers of patients. This result is consistent with the improvement of the physical health dimension and is disparate with mental health dimension. Baghcheki and Koohestani ${ }^{27}$ studied the relationship between the incapacity of the elderly with stroke and quality of life of caregivers before and after discharge. The results showed that quality of life of the main caregivers of the stroke patients decreases after a patient's discharge, and they need help and support for adaptation to lifestyle changes. ${ }^{27}$ Although care and support 
care for the caregivers are important, studies show that due to the focus of the system on the patients themselves and the lack of proper communication with their families, these studies are often not well considered or supported. ${ }^{28}$ Although it is important to care and support carers, studies have shown that due to the focus of the system on patients themselves and the lack of proper communication with families, they are often not given adequate attention and support. Focus on family as part of a patient's treatment and care program has been eliminated from interventional studies and general clinical practice. ${ }^{29}$ Empowering a family based on the involvement of family members to solve a problem may be an effective step to help family members. This activity will increase their caregiving knowledge and reduce their physical and emotional stresses. So they can improve their patient's condition. ${ }^{30}$

Providing an appropriate training and support package for stroke patients and caregivers will help to increase their level of satisfaction as they need to obtain accurate and reliable information on the disease and its care. ${ }^{31,32}$

\section{Conclusion}

Training patient care reduces the burden of care and improves quality of life in caregivers of stroke patients. Hence, family education should be set as a priority of nursing and discharge procedures to reduce the complications of caring for stroke patients.

\section{Acknowledgments}

The researchers would like to thank families of patients admitted to the ICU of Alzahra Hospital in Isfahan, Iran, and the Deputy of Research, Arak University of Medical Sciences, Arak, Iran.

\section{Disclosure}

The authors report no conflicts of interest in this work.

\section{References}

1. Urden Lindads, Lough KM, Mary E. Priorities in Critical Care Nursing. New York: Mosby; 2008:361.

2. Morton PG, Fontaine DK. Essentials of Critical Care Nursing: A Holistic Approach. New York: Wolters Kluwer; 2013:329.

3. Chulay M, Burns, Suzanne M. AACN Essentials of Critical Care Nursing. New York: McGraw-Hill; 2010; P: 378.

4. Smeltzer, Bare SC, Brenda G. Hinkle Janice Cheever Kerry H. Textbook of Medical-Surgical Nursing. New York: Wolters Kluwer; 2008; P:543.

5. Azarpazhooh MR, Etemadi MM, Donnan GA, et al. Excessive incidence of stroke in Iran: evidence from the Mashhad stroke incidence study (MSIS), a population-based study of stroke in the Middle East. Stroke. 2010;41:e3-e10.

6. Alimohammadi N, Maleki B, Shahriari M. Effect of a care plan based on Roy adaptation model biological dimension on stroke patients' physiologic adaptation level. Iran J Nurs Midwifery Res. 2015;20(2): $275-281$.
7. King RB, Hartke RJ, Lee J, Raad J. The stroke caregiver unmet resource needs scale: development and psychometric testing. Neurosci Nurs. 2013;45(6):320-328

8. Anaraki R, Mahmoodi H, Rouhi G, Asayesh G, Nasiri H, Rakhshani H. General health status of neurologic patients' caregivers and the related factors. J Gorgan Bouyeh Faculty of Nur \& Midwif. 2013;9(2): 65-73.

9. Aynur O, Birsen I, Goksel Somay SEC, Derya Uluduz MB, Bahar Tasdelen HK. The caregiver burden and stroke prognosis. J Neurol Sci. 2009;26:632-639.

10. Mohammadi SBF, Dabbaghi F, Yadavar NM. Facilitator and barriers factors in family caregiving process of Iranian frail elderly: qualitative study. IJN. 2008;21(55):55-65.

11. Takai M, Takahashi M, Iwamitsu Y, et al. The experience of burnout among home caregivers of patients with dementia: relations to depression and quality of life. Arch Gerontol Geriatr. 2009;49(1):e1-e5.

12. Dalir M. 2009. Perceived Life Changes and Feelings of Depression in Caregivers of Persons with Stroke [thesis]. Tehran: Iran University of Medical Sciences; 2009.

13. Karahan AY, Kucuksen S, Yilmaz H, Salli A, Gungor T, Sahin M. Effects of rehabilitation services on anxiety, depression, care-giving burden and perceived social support of stroke caregivers. Acta Medica (Hradec Kralove). 2014;57(2):68-72.

14. Carretero S, Garcés J, Ródenas F, Sanjosé V. The informal caregiver's burden of dependent people: theory and empirical review. Arch Gerontol Geriatr. 2009;49(1):74-79.

15. Shynequria D. African American Caregiver's Level of Knowledge About Alzheimer's Disease and its Relationships to Psychological Stress [thesis]. Tallahassee, FL: Florida State University; 2006:P.1-8.

16. Jorstad M. Perceived Life changes and Feelings of Depression in Caregivers of Persons with Stroke [thesis and dissertation]. 2004; 15-11.

17. Koohestani HR, Baghcheghi N. Burn out in caregivers of patients with stroke and its related factors. Hakim Res J. 2012;14(4):242-248.

18. Tabrizi LB, Navab E, Afshar PF, Noghabi AAA, Haghani H. Effect of cognitive-behavioral intervention on burden of family caregivers of patients with Alzheimer's disease. J Hayat. 2015;21(1):94-102.

19. Gholizade M, Akrami R, Tadayonfar M, Akbarzadeh R. An evaluation on the effectiveness of patient care education on quality of life of stroke caregivers: a randomized field trial. J Sabzevar Uni Med Sci. 2016;22(6):955-964.

20. Gutiérrez-Maldonado J, Caqueo-Urízar A, Kavanagh DJ. Burden of care and general health in families of patients with schizophrenia. Soc Psychiatry Psychiatr Epidemiol. 2005;40(11):899-904.

21. Gutiérrez-Maldonado J, Caqueo-Urízar A. Effectiveness of a psychoeducational intervention for reducing burden in Latin American families of patients with schizophrenia. Qual Life Res. 2007;16(5):739-747.

22. Hoseini RS. Relationship between general health and burden in female caregivers of patients with Alzheimer disease. J Sabzevar Uni Med Sci. 2015;21(6):9-15.

23. Mirza AS, Shohreh S, Memarian R, Vanaki Z. The evaluation of effect case management program on quality of life of pre-school children with hemophilia. Quarterly J Nurs Manag. 2013;2(1):38-47.

24. Ain QU, Dar NZ, Ahmad A, Munzar S, Yousafzai AW, Wahab A. Caregiver stress in stroke survivor: data from a tertiary care hospital - cross sectional survey. BMC Psychol. 2014;2(1):49.

25. Andrén S, Elmståhl S. Relationships between income, subjective health and caregiver burden in caregivers of people with dementia in group living care: a cross-sectional community-based study. Int J Nurs Stud. 2007;44(3):435-446.

26. Opara JA, Jaracz K. Quality of life of post-stroke patients and their caregivers. J Med Life. 2010;3(3):216-220.

27. Baghcheghi N, Koohestani HM. Quality of life of caregivers of elderly people with stroke at the hospitalization time and after leaving hospital, and its association with patients disabilities. J Arak Uni Med Sci. 2011;21(74):16-25.

28. Molloy GJ, Johnston DW, Witham MD. Family caregiving and congestive heart failure. Review and analysis. Eur J Heart Fail. 2005;7(4):592-603. 
29. Clark AM, Freydberg CN, McAlister FA, Tsuyuki RT, Armstrong PW, Strain LA. Patient and informal caregivers' knowledge of heart failure: necessary but insufficient for effective self-care. Eur J Heart Fail. 2009;11(6):617-621.

30. Kheirollahi N, Khatiban M, Oshvandi KH, Alhani F, Fardmal J. The effect of intervention based on family-centered empowerment on perceived severity of threat in caregivers of patients with stroke: a semi experimental study. Sci J Hamadan Nurs Midwifert Fac. 2014;22(3):73-82.
31. Eames S, Hoffmann T, Worrall L, Read S, Wong A. Randomised controlled trial of an education and support package for stroke patients and their carers. BMJ Open. 2013;3(5):e002538.

32. Pierce LL, Steiner V. Usage and design evaluation by family caregivers of a stroke intervention web site. J Neurosci Nurs. 2013;45(5):254-261.
Journal of Multidisciplinary Healthcare

\section{Publish your work in this journal}

The Journal of Multidisciplinary Healthcare is an international, peerreviewed open-access journal that aims to represent and publish research in healthcare areas delivered by practitioners of different disciplines. This includes studies and reviews conducted by multidisciplinary teams as well as research which evaluates the results or conduct of such teams or health

\section{Dovepress}

care processes in general. The journal covers a very wide range of areas and welcomes submissions from practitioners at all levels, from all over the world. The manuscript management system is completely online and includes a very quick and fair peer-review system. Visit http://www.dovepress.com/ testimonials.php to read real quotes from published authors.

Submit your manuscript here: https://www.dovepress.com/journal-of-multidisciplinary-healthcare-journal 